To tap through solid lung and adherent pleura does not seem so very serious a matter, and if a gangrenous cavity is advancing towards the surface of the lung surrounded by so feeble a zone of inflammation as not to set up adhesion of the pleural surfaces, tapping would seem only to hasten by a little what would inevitably soon occur of itself, with this compensatory advantage, that, instead of a closed empyema, an open one would result; the incision which caused the empyema being also the most essential thing for its relief.

I. think, then, that, although many observations are required before the indications for the operation of incision in gangrene of the lung can be definitely laid down, it is probable that the following will be found a fair tentative proposition :- That when (I) the opening through the bronchi seems to be inefficient as an exit for the fluid, or the passage of the gangrenous ichor seems to be setting up irritation in the bronchial mucous membrane, $(2)$ the patient appearing to sink rather than to rally, and (3) auscultatory evidence of a cavity can be heard, an incision with a view to drainage is justifiable.

Halifax, Yorkshire.

\section{A CASE OF POISONING BY DRINKING "CAMPHORATED OIL."}

BY H. BENDELACK HEWETSON, M.R.C.S.

Mx object in reporting the details of the following case is to draw attention to the sale of a decidedly poisonous and frequently used liniment, in ordinary bottles, without any other label than that which states what the bottle contains, without regard to its poisonous properties; besides the interest attaching to the relation of the clinical aspects and symptoms of a rare kind of poisoning.

On Sunday, November 23rd last, at 2.30 A.M., I was called to attend Miss B-C, aged twenty-five, whose violent cries and wild delirium had already roused the neighbours, she having retired quietly to bed at 11.45 on Saturday night with the intention of taking a dose of castor oil. On reaching the house a quarter of an hour later, I found the patient in bed delirious and vomiting, her eyes staring wildly around, without power to recognise even the nearest relative, whom she accused of doing her injury. Her only occasional complaints were that she felt sick and cold, and that her cheeks tingled very much. These expressions were given vent to at intervals. In the meantime the breathing appeared laboured; pulse 104, firm and good. The extremities did not feel cold to the touch. The vomit and breath smelt strongly of camphor, and a corked, twoounce, clear-glass, medicine bottle, upon the dressing-table, out of which she was supposed by her relatives to have taken her intended dose of castor oil, also smelt of camphor. I quickly gave her the only emetic at hand, strong hot mustard and water, which made her vomit considerably, after which there was no further vomiting; and by 3.30 she had almost regained sufficient consciousness to enable me to talk to her, and corroborate the evidence (which she did) given by the relatives in the following story.

On Saturday evening she and a younger sister called at a chemist's shop, taking with them a two-ounce bottle, which the family were accustomed to keep filled with castor oil. Both the patient and her sister assert that they asked for castor oil. On getting outside the shop the patient noticed that what was in the bottle, half filling it, "did not look like castor oil"; "it was thinner." Making no further remark, and not noticing the new white label with the name of the chemist, and simply "Camphorated oil" printed upon it, she retired to bed at a quarter to twelve, and took half the bottleful of what she understood to be castor oil. She says that she noticed the altered name upon the label, but in her ignorance thought that because it did not say "Not to be taken" upon the bottle, or "Poison," it was all right, and that this was only a new name for a "better kind" of castor oil. In answer to my question as to the taste, she replied that that confirmed her idea that it was a dose of " improved castor oil," because it "felt sharp." After taking the dose she appears to have gone to bed and slept until 1.30, at which time she roused a sister, who slept with her, by her delirium and wandering conversation. For the next half hour the delirium increased, rousing the neighbour- hood by her shouts and violence, but she did not endearour to get out of bed, merely throwing herself about in bed. The delirious symptoms were distinctly diminished by the vomiting until 2.40 , when I saw her myself.

By 4 o'clock she had become quite clear-headed and rational, only complaining of headache and feeling cold and sickly. During the day she became convalescent, and the improvement continues, although she is still confined to bed, In consequence of this case I was led to look through the Pharmacy Act relating to the sale of poisons, and found that "camphor liniment" does not come under the head of poisons, and that it can be sold with an ordinary label, without even the warning "not to be taken." From this it would appear that, although this accident is of rare possibility, yet as the law now stands an ignorant person may be supplied with " camphor liniment" without a warning as to the nature of the drug or any hint that, should they teel so inclined, it may be swallowed with impunity. Doubtless the risk is rare, but so long as it exists it would be wiser to provide against the possibility of its occurrence, which may lead to the production of symptoms of an alarming, if not absolutely fatal, nature.

Leeds.

\section{CASE OF DYSMENORRHEA, ACCOMPANIED BY FITS OF A TETANIC NATURE.}

\section{By JAMES LATTEY, L.R.C.P., \&c.}

THE following case may be interesting as showing how severe painful obstruction will sometimes yield to perseverance in treatment.

The subject of this note, Mrs. H. R_- aged twenty-one, a well-developed brunette, arrived at Southampton from Natal on the evening of December 19th, 1878, and came up to London the next day, when I was sent for to see her. She had been very well during the passage home. She com. menced to menstruate on the 19th. I found her sitting doubled up on the bed, with a large hot-water tin pressed as closely as possible to the lower part of the abdomen, the only arrangement, she said, that gave her relief. The discharge was scanty, light-coloured, and mixed with small clots and shreds like membrane. The pain was intense-agony she called it-especially when a clot was passing. I ordered her twenty grains of choral, with an equal quantity of bromide of potassium every four hours till the pain stopped; and I am bound to say it did her no good whatever. I may as well mention here that, although I tried all kinds of sedatives by the mouth and even by the rectum, when she was menstruating, they seemed to have no effect.

The next morning I heard the following particulars. She was born and lived in Natal. Had been married two years and eight months; never been pregnant; menstruated first when fourteen and a half years old, and always suffered severely for the first two or three days. Once she had a slight fit, similar to those I saw later on; this was when she was unwell during an attack of measles; otherwise she is always healthy and strong, and laughs at the idea of hysteria, and indeed there is nothing in her appearance or manner suggestive of that peculiarity; she has not suffered from fever of any kind. Since her marriage the symptoms have been increasing in severity. At the beginning of last year she became much worse, and went to Pre. toria, to see if she could get some relief. She was under a medical man there for several months, who dilated the os uteri with tents, having to use chloroform and subcutaneous injections of morphia very freely; he wished to make incisions, but she was so weak she could hardly stand, and could not make up her mind to bear it. Just at this time she had to leave for England.

On Dec. 2lst she was turning and twisting herself, on and off the bed, in extreme pain. I injected half a grain of morphia and one-eightieth of a grain of atropine under the skin; and she commenced inhaling chloroform till the sedative took effect, but before she could have taken more than a few drops her eyes turned inwards, a horrible grin came over her face, and her body was strongly arched backwards, her head being so turned under her shoulders as to be resting almost on her forehead; no amount of pressure would get her body down, and I was obliged to hold her up, for fear she should get smothered in the bedclothes. She re- 
mained in this state for two or three minutes, and then the muscles relaxed, but she was unconscious for about a quarter of an hour. This attack was repeated several times, and during three different periods afterwards. I thought perhaps the remedies had something to do with it, but the fits oc curred later on before any drug had been used. She was kept more or less under morphia and chloroform for three days, when the pain ceased; and after some sickness she was perfectly well.

Subsequently I found the os uteri extremely small, and could only pass a tent the size of a No. 1 gum catheter. When this commenced to swell the pain became intense, and morphia and chloroform were brought into action freely. The next day I divided the lower half of the neck of the womb in four directions, and passed a sound into the cavity itself. I noticed in doing so that there was a spot about two-thirds of the way through, which was intensely painful when touched, but there was no obstruction from it. I passed the sound several times at intervals of three or four days, but contraction gradually took place, except at the lower segment; and on the 2lst, when she was unwell, the former scenes of misery were repeated.

During the early part of February I kept the nassage dilated every other day with tents, and at the end of the month there was very little suffering - so little that I thought she was safe; but on March 25th she relapsed, and had some of the former fits, though the pain did not continue for so many days. I dilated again with the sound and tents during April, but with no better result. She had suffered so much that her near relations tried to dissuade me, and did up till this time, from operating any furthur; but the patient herself was anxious that everything possible should be tried, and accordingly, after consulting with my partner, Mr. Hume, who had watched the case all through, and given me many valuable hints, I determined to divide the whole canal up to the internal os; I did so on May 9th, cutting in two directions, and passed the sound every other day without the old pain, till the 26 th, when she was unwell. She suffered slight pain for one day, and I was afraid contraction might take place again.

On June 6th, I divided the internal os thoroughly in three directions, passing the knife quite into the uterus, and afterwards plugged the neck throughout with a piece of elastic catheter, wound round with lint soaked in carbolised oil. On the 24th she menstruated quite naturally; there were no clots, and the discharge was of a proper colour and quantity. I took the precaution of passing the sound periodically for a month afterwards, and then inserted a divided stem pessary with a spring outwards, but it would not stay in more than a week. From June till the present time she has had no pain whaterer, and the sound passes very freely, almost without her knowing it.

My impression, on seeing this case at first, was that the obstruction confined itself, most likely, to the lower segment of the neck, and especially to the os uteri ; and I was unwilling to divide it throughout its course for fear of exciting inflammation; as it was, directly after the operation of May 9th the abdomen became intensely tender, there was great pain in the back and down the legs, and for three or four days some amount of fever. The symptoms gradually passed off in the course of ten days under the free use of opium, but I consider they justified the caution used in not dividing the internal os till every other means had been tried and failed, and nothing but a life of misery remained for my patient to contemplate.

Kensington.

\section{CASE OF GANGRENE OF RIGHT LUNG WITH CARIES OF SPINAL COLUMN,}

FROM PASSAGE OF HEAU OF GRASS INTO BRONCHUS.

BY JOHN MAGRATH, M.D.,

LATE PHTSICLAN TO THE EAST IONDON HOSPITAL FOR CHYLDREN, ETC.

Tre following case appears to me to be worthy of record, as offering several points of interest in the clinical history of pulmonary gangrene, besides being an additional illustration of the lecture by Dr. George Johnson, as lately published in THE LANCET.

J. S-_-, aged seven years, was brought to me on July Sth, 1878, with the following history:-Some hours previously he accidentally "swallowed" a head of grass. A violent fit of coughing, with lividity of face, immediately followed, but the urgency soon subsided, and when the patient was seen by me, there was no physical sign of obstructed respiration. An occasional dry rhonchus was the only auscultatory sound, and the patient complained merely of dryness of throat and a slight pain to right of epigastrium. Large doses of ipecacuanha were administered, and afterwards purgatives, but though the evacuations were carefully examined, nothing was discovered. It was hoped (from the slight synuptoms), notwithstanding, that the grass was actually swallowed, and that if it entered the larynx at all, it was got rid of immediately by the violent respiratory efforts.

After an interval of about a month, the patient was again brought to me. Now a good deal of pain was complained of on the right side, rather indefinite as to position, but soon becoming tolerably well localised, and described as starting from the right infra-mammary region, and going through to the back. A hacking cough followed, and some elevation of temperature, with harsh breathing and some dry rhonchus as the only physical signs. The cough gradually became more troublesome and the pain distressing, being now referred more particularly to an area of a few square inches below the angle of the scapula and approaching the spinal column. Evidence of consolidation of lung over the site of pain manifested itself about eight weeks after the accident. The dulness, at first very slight, became complete in about a fortnight, or ten weeks after the date of "swallowing" the grass. The area of dulness was quite circumscribed, and was confined to the posterior base below the scapula. The breath-sounds, at first weak, became distinctly tubular, and afterwards cavernous, with a good deal of coarse bubbling rhonchus, after the tenth week. This was over the region of consolidation; elsewhere the respiration was not far from normal.

About the tenth week the patient was distressed with pain and could lie on right side only. Rigors followed. The expectoration, at first very scanty and tinged with blood, was now profuse, purulent, and most foul. It soon became dark, and the stench of the breath almost intolerable. At this time also pressure over the area of dulness caused considerable pain, and two of the dorsal vertebral spines were noticed to be very prominent.

Profuse sweats set in, with delirium, and death followed twelve weeks after the accident.

Autopsy, eighteen hours after death.-In this I was assisted by Mr. Mahony, a neighbouring practitioner, who also saw the case during life. About one-third of lower lobe of right ling was found to be completely gangrenous, the pulmonary tissue breaking down under the least pressure. The centre of this gangrenous mass was riddled by cavities, and in one of these lay a head of grass, blackened, but scarcely altered in consistence, and about three-quarters of an inch long. The apex of the grass was pointed downwards, the grain thus aiding the inspiratory efforts, but resisting the expiratory efforts to expel. The gangrenous lung was in separably adherent to surrounding tissues. The diaphragm was perforated, and the upper surface of the liver was inflamed, and in parts beginning to soften. The bodies of two contiguous dorsal vertebræ on the right side were excavated and carious, breaking down under very gentle pressure. This condition was suspected during life, and. accounted for the angular curvature which developed so rapidly in the last few weeks of life.

East Grinstead.

Odontological Soctety of Great Britain.At the Annual General Meeting of this Society, held Jan. 12th, 1880, the following members were elected as officers and councillors for the year $1880:-$ President : Mr. Alfred J. Woodhouse. Vice-Presidents : Mr. Charles James Fox, Mr. T. A. Rogers, Dr. J. Walker, Mr. David Hepburn (Edinburgh), Mr. Alfred Meara (India), Mr. J. E. Rose (Liverpool). Treasurer: Mr. James Parkinson. Libra. rian : Mr. Felix-Weiss. Curator : Mr. C. S. Tomes, F.R.S. Honorary Secretaries: Mr. Ashley Barrett, Mr. S. J. Hutchinson, Mr. F. Canton. Councillors: Messrs. E. B. West, J. S. Turner, T. Underwood, Oakley Coles, W. H. Woodhouse, Edwin Saunders, T. C. White, G. Wallis, W. F. Henry, J. Doherty (Dublin), W. R. Wood (Brighton), WV. Hunt (Yeovil), T. WV. G. Palmer (Cheltenham), T. J. Brown Mason (Exeter), WV. Williamson (Aberdeen). 